\title{
LOW BACKGROUND LIQUID SCINTILLATION COUNTING USING AN ACTIVE SAMPLE HOLDER AND PULSE DISCRIMINATION ELECTRONICS
}

\author{
JOHN E NOAKES \\ Center for Applied Isotope Studies \\ University of Georgia \\ Athens, Georgia 30605 \\ and \\ ROBERT J VALENTA \\ Packard Instrument Company \\ Downers Grove, Illinois 60515
}

\begin{abstract}
A Packard low-level liquid scintillation counting system is described which provides superior low-background beta-counting capability for ${ }^{3} \mathrm{H}$ and ${ }^{14} \mathrm{C}$. The design is based on a novel pulse-discrimination circuit that separates background from valid scintillation pulses. Background discrimination is further enhanced by adding a plastic vial holder that acts as an anticoincidence guard. When excited by background radiation, the scintillation properties of the plastic provide an increased burst of photons to the detection electronics, which discriminate based on the number of component pulses in the burst. Experimental data demonstrate the low-level counting capabilities of this counter.
\end{abstract}

\section{INTRODUCTION}

Liquid scintillation counting is commonly used for the measurement and quantification of environmentally low levels of ${ }^{14} \mathrm{C}$ and ${ }^{3} \mathrm{H}$. A suitable counting system used in environmental analysis must have low instrument background and high radionuclide counting efficiency to provide maximum measurement sensitivity.

Electronic methods using pulse processing techniques to reduce instrument background have been investigated. Using selective pulse height discrimination, Laney (1971) reported that most of the phototube cross-talk produced by radioactive contamination and Cerenkov radiation in the phototube envelope can be rejected by analyzing relative pulse amplitude at each phototube output. Noakes and Spaulding (1980) and Kalish et al (1979) evaluated pulse-shape discrimination techniques using a $\mathrm{NaI}(\mathrm{Tl})$ "seethrough" detector optically coupled to both the sample vial and two diaxially opposed photomultiplier tubes.

Jerde, Peterson and Stein (1967) indicated that high-energy radiation incident upon a photomultiplier tube produced two types of background noise: one large pulse with trailing smaller pulses, or "bursts", thought to be caused by either random cosmic rays or background induced by short wave-length Cerenkov events. Roodbergen, Kroondijk and Verhuel (1972) observed smaller pulses following photoelectron pulses induced by a gamma-ray source, but could not explain the trailing pulses. Using the difference in pulse shape of the scintillation events produced by electrons and protons, Owen (1961) was able to discriminate between gamma-ray-induced and neutron-induced pulses. Broek and Anderson (1960) reported the slow burst component to be .001 times the signal produced by the large prompt component. 


\section{METHODS}

In 1985, Packard Instrument Company developed the first electronic burst counting circuitry (Valenta, 1987) for use in a commercial liquid scintillation counter. The burst counting system was designed to count the number of smaller burst pulses trailing the larger prompt coincident scintillation pulse (Fig 1). The number of burst afterpulses was used to discriminate valid scintillation events from background events in typical laboratoryprepared samples that had not been purged of oxygen.

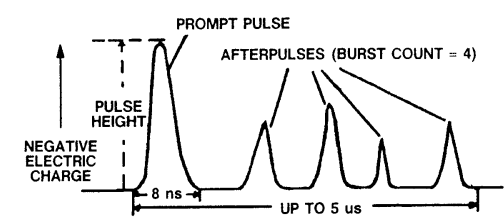

Fig 1. Typical coincident scintillation pulse followed by afterpulses

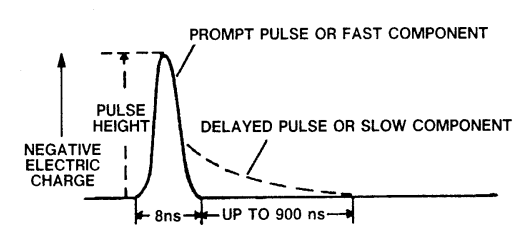

Fig 2. A typical unquenched coincident scintillation pulse consisting of the prompt fast component and a delayed component which can extend to as long as 900 nanoseconds. The delayed component is not observed in quenched samples.

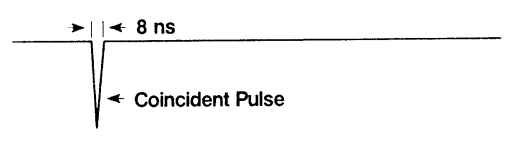

Fig 3. Typical sample scintillation pulse with no trailing afterpulses

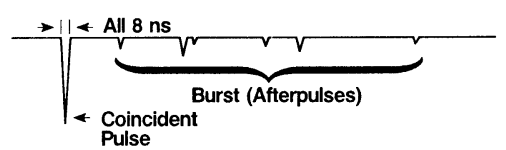

Fig 4. Typical background scintillation pulse showing trailing afterpulses with pulse amplitudes similar to single photons 
A typical scintillation event (Horrocks, 1974) is composed of at least two components (Fig 2): a fast or prompt component due to the fluorescence of the scintillators (2-8 nanoseconds) and a slower or delayed component due to the decay of the triplet excited molecules (200-900 nanoseconds). The slow component (Laustriat, 1968) is due to the annihilation of the two triplet excited molecules, and is detected in unquenched samples. Dissolved oxygen or other quenching agents have little effect on the prompt component, but eliminate the slow component.

\section{Burst Counting Theory of Operation}

The burst counting technique is based on a comparison of pulse characteristics between sample scintillation (Fig 3) and background scintillation pulses (Fig 4). Most background pulses detected by the coincidence circuit are accompanied by a series of randomly spaced smaller energy pulses.

Background scintillations are coincident in nature and are ordinarily interpreted by the electronic circuitry in a similar manner as scintillations caused by emission from the sample. However, background scintillations emitted by the sample vial glass, phototube glass and surrounding material scintillate with a significantly longer decay time. Background radiation produces an initial coincident pulse followed by a delayed burst of photons. This contrasts with a single fast coincident pulse produced by sample activity followed by very few or no afterpulses. This difference in pulse characteristics is used in the burst counting technique to discriminate background noise from sample radioactive decay events.

To count the afterpulses, the output of both photomultiplier tubes is tracked for five microseconds after coincident pulse detection. The burst counting system counts and stores afterpulse information. A particular coincident pulse is rejected by comparing the counted burst pulses to a certain minimal "noise" threshold number of burst pulses which varies with the energy of the coincident event.

A plastic vial holder, impregnated with scintillators having a long decay constant surrounds the sample vial to further increase photons in the trailing burst due to background radiation (Fig 5). Similar material, herein termed the "auxiliary scintillator" was molded into a shape that would serve as a

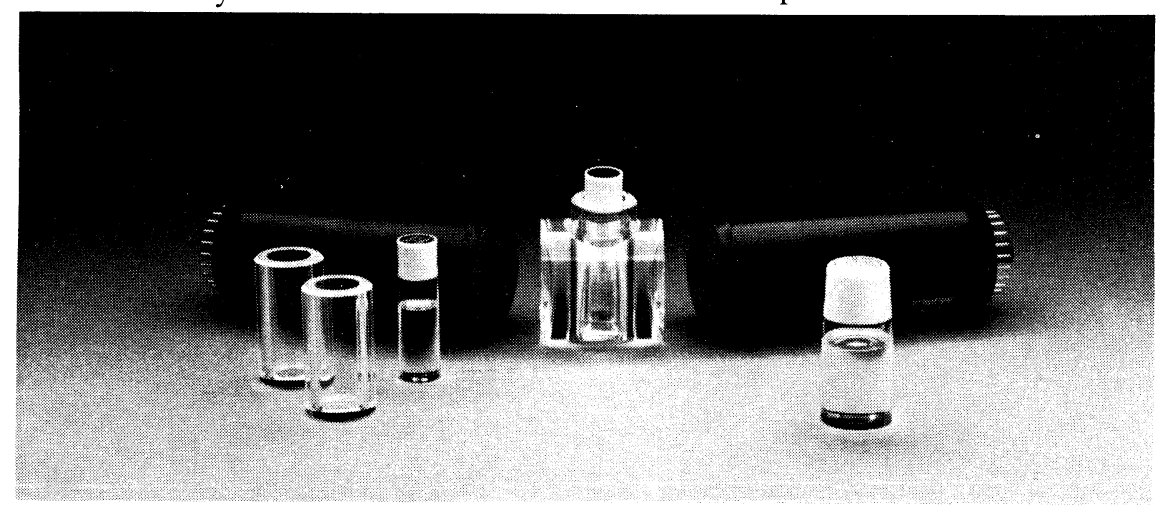

Fig 6. The auxiliary scintillator vial holders and detector guard with photomultiplier tubes and scintillation vials. The vial holder can be used as an adapter for $7 \mathrm{cc}$ size vials to provide additional shielding. 
guard, light pipe and reflector when coupled to both photomultiplier tubes. The detector guard has a central through-hole to accommodate both large $(22 \mathrm{cc})$ and small $(7 \mathrm{cc})$ scintillation vials, and a vial holder containing a $7 \mathrm{cc}$ vial (Fig 6). In this configuration, scintillation photons pass through the plastic vial holder and detector guard (both auxiliary scintillators) to reach the photomultiplier tubes, which view the sample, the vial holder and the detector guard.

\section{Spectral Distribution}

The added dimension of burst counts transforms the conventional planar energy spectrum plots of the sample and background into threedimensional surfaces. This provides the ability to establish rectangular counting regions in the energy-burst plane, which can be used to exclude background counts from the accumulated data. Figure 7 shows the pulse-height distribution of background counts and Figure 8 shows ${ }^{14} \mathrm{C}$

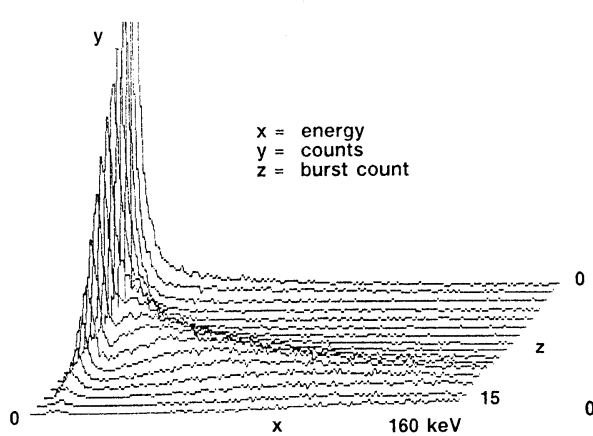

Fig 7. Three-dimensional graph representation of the background count distribution as a function of pulse energy and burst count

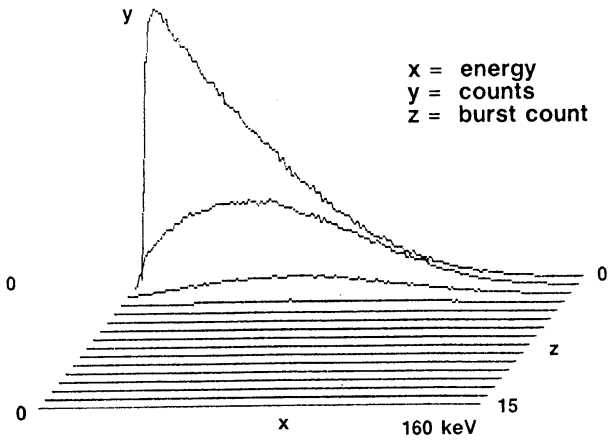

Fig 8. Three-dimensional graph representation of the ${ }^{14} \mathrm{C}$ count distribution as a function of pulse energy and burst count

counts in the energy-burst plane. ${ }^{14} \mathrm{C}$ counts dominate the lower burst numbers and background counts extend into higher burst number regions. Hence, the number of afterpulses (burst count) following the coincident pulse can be used to discriminate against background. To separate ${ }^{14} \mathrm{C}$ pulses from background pulses, the coincident events which are accompanied by bursts exceeding the allowed number for that particular counting region are rejected.

By reducing the number of burst planes from the acceptance criteria, the background is reduced. However, since ${ }^{14} \mathrm{C}$ produces counts in the $1 \mathrm{st}$ and 2nd burst planes, inclusion of these planes in the rejection criteria also reduces ${ }^{14} \mathrm{C}$ counting efficiency. Various counting regions in the energyburst plane are programmed into the discrimination electronics and may be selected based on the required counting efficiency and amount of background discrimination. 


\section{Plastic Scintillator Guard and Vial Holder}

Noakes and Spaulding (1980) developed a "see-through" NaI(Tl) crystal which was used to discriminate beta-gamma events. The crystal was mounted around the liquid scintillation sample so that the two photomultiplier tubes could view the sample. The $\mathrm{NaI}(\mathrm{Tl})$ crystal provided a slow rise-time pulse which was discriminated from the faster rise-time pulse of the liquid cocktail, and was also used as an active guard for background discrimination using pulse-shape analysis.

After studying burst counting discrimination as a beta pulse validation scheme, it was apparent that a difference of a few afterpulses immediately following a coincident event could affect discrimination performance. To improve detection capability of the burst counting electronics, the number of afterpulses required amplification. It was thought that a long decay time auxiliary scintillator would provide an increased number of afterpulses. Discrimination of background necessitated placement of the slow fluor scintillator outside of the sample. Thus, when the slow fluor outside the sample was excited by a high-energy background source, eg, cosmic radiation, and produced a coincident event within the sample, the phosphorescence of the slow fluor scintillator would provide an amplified burst.

A blend of both primary and secondary scintillators that would produce a long decay time was fabricated into a suitable plastic matrix. The plastic material was formed in the shape of a vial holder (7cc vials, Fig 6) and detector guard that filled the void between the sample and the photomultiplier tubes. The plastic detector guard was optically coupled to the face of each photomultiplier tube and coated with a reflective material. The scintillating plastic vial holder and detector guard have good optical transmittance in the range of 4000 to 5000 angstroms. The decay time of the slower component of the plastic scintillators is ca 250 nanoseconds. The vial holder can be used alone or in conjunction with a permanently installed detector guard for enhanced background reduction capabilities.

RESULTS AND DISCUSSION

Refrigerated Packard Tri-Carb 2250 series liquid scintillation analyzers were used in all counting experiments. Scintillation samples containing known amounts of ${ }^{14} \mathrm{C}$ in toluene, and ${ }^{3} \mathrm{H}$ in toluene or water, were prepared in both standard $(22 \mathrm{cc})$ and small $(7 \mathrm{cc})$ low-potassium glass vials previously washed in a solution of 0.1M EDTA to remove surface-associated radioactivity. Teflon ${ }^{\mathrm{R} 1}$ vial cap liners were used to inhibit solvent and toluene evaporation after sample preparation. Similar background samples were prepared in a corresponding manner. Background samples were counted with repeat counts of $100 \mathrm{~min}$ each, and radioactive samples were counted for 10 min each. The scintillation cocktail used in the $\mathrm{E}^{2} / \mathrm{B}$ experiments consisted of PPO $(6 \mathrm{~g} / \mathrm{L})$ and POPOP $(0.2 \mathrm{~g} / \mathrm{L})$ in benzene.

\section{Plastic Slow Fluor Scintillator}

Optical absorption and emission spectra of the plastic auxiliary scintillators were compared to other common scintillators and blends thereof.

\footnotetext{
${ }^{1}$ Teflon is a registered trademark of E I DuPont deNemours and Co.
} 
TABLE 1

Optical absorption and emission properties of commonly used scintillators in low-level counting applications

\begin{tabular}{|c|c|c|c|}
\hline $\begin{array}{c}\text { Primary } \\
\text { Scintillator }\end{array}$ & $\begin{array}{c}\text { Secondary } \\
\text { Scintillator }\end{array}$ & $\begin{array}{c}\text { Absorption Max. } \\
\text { Wavelength }\end{array}$ & $\begin{array}{c}\text { Emission Max. } \\
\text { Wavelength }\end{array}$ \\
\hline Plastic Slow Fluor & Not listed & 410 & 425 \\
\hline $\begin{array}{c}\text { Butyl-PBD } \\
15 \text { grams/liter }\end{array}$ & None & 357 & 365 \\
\hline $\begin{array}{c}\text { PPO } \\
6 \text { grams/liter }\end{array}$ & $\begin{array}{c}\text { POPOP } \\
\text { gram/liter }\end{array}$ & 396 & 415 \\
\hline $\begin{array}{c}\text { Butyl-PBD } \\
15 \text { grams/liter }\end{array}$ & $\begin{array}{c}\text { DPA } \\
\text { grams/liter }\end{array}$ & 420 & 430 \\
\hline $\begin{array}{c}\text { Butyl-PBD } \\
15 \text { grams/liter }\end{array}$ & $\begin{array}{c}\text { Bis-MSB } \\
0.2 \text { gram/liter }\end{array}$ & 409 & 412 \\
\hline $\begin{array}{c}\text { BBOT } \\
6 \text { grams/liter }\end{array}$ & $\begin{array}{c}\text { Bram/liter } \\
\text { gram }\end{array}$ & 415 & 431 \\
\hline
\end{tabular}

Absorption/emission spectra were measured for a $1 \mathrm{~cm}^{2}$ ingot of plastic material (Table 1). The maximum absorption and emission wave lengths were ca 410 and 425 nanometers, respectively.

The plastic scintillator contains a proprietary blend of both primary and secondary scintillators. Use of a scintillator with emission characteristics that largely overlap the absorption spectrum of the plastic, such as butylPBD, resulted in reduced efficiency when counting with this scintillator using the plastic vial holder and/or detector guard. The addition of a secondary scintillator wave shifter to a cocktail containing butyl-PBD, such as BBOT, DPA, POPOP or Bis-MSB, acted to restore the counting efficiency.

\section{Figure of Merit Counting Performance}

$\mathrm{E}^{2} / \mathrm{B}$ performance was compared for the various burst counting discrimination modes and presence of auxiliary scintillator (vial holder or detector guard). In these experiments, a benzene scintillator consisting of PPO $(6 \mathrm{~g} / \mathrm{L})$ and POPOP $(0.2 \mathrm{~g} / \mathrm{L})$ was used in the preparation of ${ }^{14} \mathrm{C}$ and ${ }^{3} \mathrm{H}$ radioactive and background samples. Table 2 shows the $\mathrm{E}^{2} / \mathrm{B}$ values obtained for each mode of discrimination and sample configuration for ${ }^{14} \mathrm{C}$; Table 3 for ${ }^{3} \mathrm{H}$.

As the amount of burst count discrimination is increased, the optimum counting region for ${ }^{14} \mathrm{C}$ and ${ }^{3} \mathrm{H}$ changes and is determined individually for each particular sample and configuration. In comparing no burst counting discrimination to maximum discrimination with no auxiliary scintillator, ${ }^{14} \mathrm{C}$ 
TABLE 2

Counting performance data for ${ }^{14} \mathrm{C}$ in benzene scintillator

\begin{tabular}{|c|c|c|c|c|c|c|}
\hline $\begin{array}{l}\text { DISCRIM- } \\
\text { INATION } \\
\text { MODE }\end{array}$ & $\begin{array}{l}\text { SAMPLE } \\
\text { CONFIG- } \\
\text { URATION }\end{array}$ & $\begin{array}{c}\text { OPTIMUM }^{4} \\
\text { ENERGY } \\
\text { REGION keV }\end{array}$ & $\begin{array}{l}{ }^{14} \mathrm{C} \% \\
\text { EFFICIENCY }\end{array}$ & $\begin{array}{l}\text { BACKGROUND } \\
\overline{C P M} \pm \sigma_{o b}\end{array}$ & $\begin{array}{c}\sigma \text { RATIO } \\
\text { BACKGROUND }\end{array}$ & $E^{2} / B$ \\
\hline none $^{1}$ & $\begin{array}{l}\text { sample } \\
\text { only }\end{array}$ & $20-103$ & 64.99 & $\begin{array}{c}3.62 \pm 0.19 \\
(12)^{5}\end{array}$ & 0.99 & 1167 \\
\hline minimum $^{1}$ & $\begin{array}{l}\text { sample } \\
\text { only }\end{array}$ & $20.5-101.5$ & 64.03 & $\begin{array}{c}3.28 \pm 0.19 \\
(12)^{5}\end{array}$ & 1.03 & 1250 \\
\hline maximum $^{1}$ & $\begin{array}{l}\text { sample } \\
\text { only }\end{array}$ & $19.5-95.5$ & 54.05 & $\begin{array}{c}0.76 \pm 0.10 \\
(12)^{5}\end{array}$ & 1.12 & 3844 \\
\hline maximum $^{1}$ & $\begin{array}{c}\text { sample }+ \\
\text { vial } \\
\text { holder }^{2}\end{array}$ & $12.5-89.5$ & 60.99 & $\begin{array}{c}0.63 \pm 0.08 \\
(17)^{5}\end{array}$ & 0.94 & 5904 \\
\hline maximum $^{1}$ & $\begin{array}{r}\text { sample + } \\
\text { detector }^{\text {guard }}{ }^{3}\end{array}$ & $10.0-81.0$ & 66.20 & $\begin{array}{c}0.51 \pm 0.06 \\
(39)^{5}\end{array}$ & 0.79 & 8593 \\
\hline maximum $^{1}$ & $\begin{array}{c}\text { sample }+ \\
\text { vial } \\
\text { holder }^{2}+ \\
\text { detector }^{2} \\
\text { guard }^{3}\end{array}$ & $11.5-81.0$ & 63.98 & $\begin{array}{c}0.43 \pm 0.06 \\
(52)^{5}\end{array}$ & 1.07 & 9520 \\
\hline
\end{tabular}

The samples were counted using a Packard Tri-Carb ${ }^{\oplus}$ series 2250 liquid scintillation spectrometer that was electronically modified to provide the different burst count discrimination mode.

The sample was ${ }^{14} \mathrm{C}$ Toluene in Benzene cocktail (PPO 6 grams/liter + POPOP 0.2 grams/liter). Total sample volume was $3.5 \mathrm{cc}$ in standard low $40 \mathrm{~K}$ glass $7 \mathrm{cc}$ vial prewashed with $0.1 \mathrm{~m}$ EDTA and Teflon $^{\oplus}$ cap liners were used.
1: Burst count discrimination mode.
2: Slow Fluor plastic vial holder, refer to Figure 6.
3: Slow fluor plastic detector guard, refer to Figure 6.
4: Energy region of interest that provided the maximum
$\mathrm{E} 2 / \mathrm{B}$ in listed discrimination mode and sample configuration. 5: Number of approximate 100 minute background count intervals
used in statistical evaluation of sigma ratio.

background was reduced by nearly $80 \%$ to produce an $\mathrm{E}^{2} / \mathrm{B}$ value of 3844 , a $229 \%$ increase. This was accompanied by a decrease of $16.87 \%$ in ${ }^{14} \mathrm{C}$ counting efficiency. $\mathrm{E}^{2} / \mathrm{B}$ values for various configurations of the sample with auxiliary scintillator can be compared to the maximum amount of discrimination without the auxiliary scintillator. Using the vial holder improved the $\mathrm{E}^{2} / \mathrm{B}$ by $54 \%$. The plastic guard increased this to $124 \%$. Finally, the full configuration of the vial holder with the detector guard improved $\mathrm{E}^{2} / \mathrm{B}$ by $148 \%$. This total increase in $\mathrm{E}^{2} / \mathrm{B}$ from 1167 to 9520 represents an improvement of $716 \%$ over the performance of a conventional liquid scintillation counter. 
TABLE 3

Counting performance data for ${ }^{3} \mathrm{H}$ in benzene scintillator

\begin{tabular}{|c|c|c|c|c|c|c|}
\hline $\begin{array}{l}\text { DISCRIM- } \\
\text { INATION } \\
\text { MODE } \\
\end{array}$ & $\begin{array}{l}\text { SAMPLE } \\
\text { CONFIG- } \\
\text { URATION } \\
\end{array}$ & \begin{tabular}{|c|} 
OPTIMUM \\
ENERGY \\
REGION keV \\
\end{tabular} & $\begin{array}{l}{ }^{3} \mathrm{H} \% \\
\text { EFFICIENCY } \\
\end{array}$ & $\begin{array}{l}\text { BACKGROUND } \\
\text { CPM } \pm \sigma_{o b}\end{array}$ & $\begin{array}{c}\sigma \text { RATIO } \\
\text { BACKGROUND }\end{array}$ & $E^{2} / B$ \\
\hline none ${ }^{1}$ & $\begin{array}{c}\text { sample } \\
\text { only }\end{array}$ & $0.5-8.5$ & 54.71 & $\underset{(12)^{5}}{10.99 \pm 0.29}$ & 0.90 & 272 \\
\hline minimum ${ }^{1}$ & $\begin{array}{l}\text { sample } \\
\text { only }\end{array}$ & $0.5-8.5$ & 54.71 & $\begin{array}{c}7.69 \pm 0.20 \\
(12)^{5}\end{array}$ & 0.74 & 389 \\
\hline $\operatorname{maximum}^{1}$ & $\begin{array}{c}\text { sample } \\
\text { only }\end{array}$ & $0.5-9.5$ & 50.94 & $\begin{array}{c}3.05 \pm 0.14 \\
(12)^{5}\end{array}$ & 0.81 & 851 \\
\hline $\operatorname{maximum}^{1}$ & $\begin{array}{c}\text { sample }+ \\
\text { vial } \\
\text { holder }^{2}\end{array}$ & $0.5-9.5$ & 49.36 & $\begin{array}{c}1.37 \pm 0.20 \\
(17)^{5}\end{array}$ & 1.60 & 1778 \\
\hline maximum ${ }^{1}$ & $\begin{array}{c}\text { sample }+ \\
\text { detector } \\
\text { guard }^{3}\end{array}$ & $2-11.5$ & 38.44 & $\begin{array}{c}0.86 \pm 0.11 \\
(39)^{5}\end{array}$ & 1.14 & 1718 \\
\hline $\operatorname{maximum}^{1}$ & $\begin{array}{c}\text { sample }+ \\
\text { vial } \\
\text { holder } \\
\text { detector }^{2} \\
\text { guard }^{3}\end{array}$ & $2-11$ & 37.13 & $\underset{(52)^{5}}{0.79 \pm 0.09}$ & 1.01 & 1745 \\
\hline
\end{tabular}

The samples were counted using a Packard Tri-Carb ${ }^{\otimes}$ series 2250 liquid scintillation spectrometer that was electronically modified to provide the different burst count discrimination mode.

The sample was ${ }^{3} \mathrm{H}$ Toluene in Benzene cocktail (PPO 6 grams/liter + POPOP 0.2 grams/liter). Total sample volume was $3.5 \mathrm{cc}$ in standard low ${ }^{40} \mathrm{~K}$ glass $7 \mathrm{cc}$ vial prewashed with $0.1 \mathrm{~m}$ EDTA and Teflon $^{\oplus}$ cap liners were used.

\footnotetext{
1: Burst count discrimination mode.

2: Slow Fluor plastic vial holder, refer to Figure 6.

3: Slow fluor plastic detector guard, refer to Figure 6.

4: Energy region of interest that provided the maximum $\mathrm{E} 2 / \mathrm{B}$ in listed discrimination mode and sample configuration.

5: Number of approximate 100 minute background count intervals used in statistical evaluation of sigma ratio.
}

Similar experiments were conducted with ${ }^{3} \mathrm{H}$ as many environmental counting applications involve the measurement of ${ }^{3} \mathrm{H}$ water. Samples and background were prepared using ${ }^{3} \mathrm{H}$ toluene of known activity. Benzene scintillators containing the same concentrations of PPO and POPOP as used in the ${ }^{14} \mathrm{C}$ experiment were used in small $7 \mathrm{cc}$ vials. Total sample and cocktail volume was $3.5 \mathrm{cc}$.

The improvement in $\mathrm{E}^{2} / \mathrm{B}$ counting performance was compared between no burst count discrimination without auxiliary scintillator and maximum burst count discrimination without auxiliary scintillator. The average background count rate was reduced from $10.99 \mathrm{cpm}$ to $3.05 \mathrm{cpm}$, a $70 \%$ reduction. ${ }^{3} \mathrm{H}$ counting efficiency was reduced slightly to $50.94 \%$ pro- 
ducing an $\mathrm{E}^{2} / \mathrm{B}$ value of 851 , which was a $213 \%$ increase from counting without burst counting discrimination. With the plastic vial holder, detector guard and combination vial holder with detector guard, background was further reduced. Maximum $\mathrm{E}^{2} / \mathrm{B}=\mathrm{ca} 1778$ was obtained using maximum burst discrimination and the vial holder only, representing an increase of $554 \%$ from no burst counting discrimination.

Apparently, use of the combination of vial holder with the detector guard reduced the tritium counting efficiency, probably due to photon absorption of the plastic. Background was reduced to ca $0.79 \mathrm{cpm}$, but this was not sufficient to provide a significantly improved $E^{2} / B$ value.

A sample containing tritiated water in PicoFluor ${ }^{R}$ LLT at $40 \%$ water load was prepared in large $(22 \mathrm{cc})$ glass scintillation vials with a corresponding background sample. The total sample volume was $20 \mathrm{cc}$. Results for different burst count discrimination modes and detector guard are shown in Table 4. Maximum $\mathrm{E}^{2} / \mathrm{B}$ was ca 247 , an increase of $191 \%$ compared to no burst counting discrimination.

TABLE 4

Counting performance data of tritiated water for direct counting applications

\begin{tabular}{|c|c|c|c|c|c|c|c|}
\hline $\begin{array}{l}\text { DISCRIM- } \\
\text { INATION } \\
\text { MODE }\end{array}$ & $\begin{array}{l}\text { SAMPLE } \\
\text { CONFIG- } \\
\text { URATION }\end{array}$ & $\begin{array}{c}\text { OPTIMUM }^{3} \\
\text { ENERGY } \\
\text { REGION keV }\end{array}$ & $\begin{array}{c}{ }^{3} \mathrm{H} \% \\
\text { EFFICIENCY } \\
\end{array}$ & $\begin{array}{c}\text { BACKGROUND } \\
\text { CPM } \pm \sigma_{o b}\end{array}$ & $\begin{array}{c}\text { o RATIO } \\
\text { BACKGROUND }\end{array}$ & $E^{2} / B$ & $\left(E^{2} \times V^{2}\right) / B$ \\
\hline none ${ }^{1}$ & $\begin{array}{c}\text { sample } \\
\text { only }\end{array}$ & $0.5-3.5$ & 22.85 & $\begin{array}{c}6.12 \pm 0.19 \\
(26)^{4}\end{array}$ & 0.78 & 85 & 5460 \\
\hline minimum $^{1}$ & $\begin{array}{l}\text { sample } \\
\text { only }\end{array}$ & $0.5-4.0$ & 25.39 & $\begin{array}{c}6.63 \pm 0.16 \\
(26)^{4}\end{array}$ & 0.61 & 97 & 6223 \\
\hline maximum $^{1}$ & $\begin{array}{c}\text { sample } \\
\text { only }\end{array}$ & $0.5-4.5$ & 25.63 & $\begin{array}{c}3.87 \pm 0.17 \\
(26)^{4}\end{array}$ & 0.88 & 170 & 10,863 \\
\hline maximum $^{1}$ & $\begin{array}{c}\text { sample }+ \\
\text { detector } \\
\text { guard }^{2}\end{array}$ & $0.5-5.5$ & 23.77 & $\underset{(28)^{4}}{2.29}+0.24$ & 1.56 & 247 & 15,791 \\
\hline
\end{tabular}

The samples were counted using a Packard Tri-Carb ${ }^{\circledR} 2250$ Series Liquid Scintillation Spectrometer that was electronically modified to provide the different burst count discrimination modes.

The sample was ${ }^{3} \mathrm{H}_{2} \mathrm{O}$ in Pico-Fluor ${ }^{\circledR L T T}$ at $40 \%$ sample load.

Total sample volume was $20 \mathrm{cc}$ (8cc sample $+12 \mathrm{cc}$ Pico-Fluor $L L T$ ). Standard low $40 \mathrm{~K} 7 \mathrm{cc}$ glass vial (22cc max. cap.) prewashed with $0.1 \mathrm{~m}$ EDTA and Teflon ${ }^{\circ}$ cap liners used.

\footnotetext{
1: Burst count discrimination mode.

2: Slow fluor plastic detector guard.

3: Energy region of interest that provided the maximum $\mathrm{E}^{2} / \mathrm{B}^{2}$ in

listed discrimination mode and sample configuration.

4: Number of approximate 100 minute background count

intervals used in statistical evaluation of sigma ratio.
} 


\section{SUMMARY}

Burst count discrimination in liquid scintillation counting illustrates a new concept of low-level counting. In the past, rigorous efforts have been applied to reduce background and cosmic radiation effects on counter components. Burst counting discrimination measures these interactions and verifies scintillation pulses. In this mode of operation, bulky, massive lead shielding, anticoincidence guard and elaborate guard electronics become less vital to background reduction. Research into specifically designed discrimination profiles may enable fine tuning of systems for operation in specific radiation background environments.

Further development of the slow fluor plastic will most probably reveal more responsive radiation-sensitive plastics with superior light transmission. It is also likely that use of the auxiliary scintillator will be expanded from detector guard and vial holder to the LS sample vial material, and may even be incorporated into the cocktail itself.

\section{ACKNOWLEDGMENTS}

The authors would like to thank F Anderson, R Culp, S de Filippis and J. Devine for their time and technical assistance.

\section{REFERENCES}

Broek, W H and Anderson, C E, 1960, The Stilbene scintillation crystal as a spectrometer for continuous fast-neutron spectra: Rev Sci Instruments v 31, no. 10, p 1063-1069.

Horrocks, D L, 1974, Applications of liquid scintillation counting: New York, Academic Press, p 276-289.

Jerde, R L, Peterson, L E and Stein, W, 1967, Effects of high energy radiations on noise pulses from photomultiplier tubes: Rev Sci Instruments, v 38, no. 10, p 1387-1395.

Kalish, Y, Sade, J, Simon, O and Simon, A, 1979, An automatic computerized alpha-betagamma scintillation spectrometer, in Internatl Jour Applied Radiation Isotopes, v 35, no. $10, \mathrm{p} 949-952$.

Laney, B H, 1971, Electronic rejection of optical crosstalk in a twin phototube scintillation counter, in Horrocks, D L and Peng, C, eds, Organic scintillators and liquid scintillation counting: New York: Academic Press, p 991-1003.

Laustriat, G, 1986, The luminescence decay of organic scintillators, in Horrocks, D L, ed, Organic scintillators: New York, Gordon and Breach, p 127.

Noakes, J E and Spaulding, J D, 1980, Pulse shape liquid scintillation counting for beta, gamma or beta-gamma counting, in Peng, C, Horrocks, D L and Alpen, E L, eds, Liquid scintillation counting: Recent applications and developments, Vol I, Physical aspects: New York, Academic Press, p 106-117.

Owen, R B, 1961, The present state of scintillation techniques, in von Koch, H and Ljungberg, G, eds, Instruments and measurements, Vol II, Nuclear instrumentation measurement of electric and magnetic quantities reactor control: New York, Academic Press, p 595-615.

Roodbergen, S, Kroondijk, R and Verhuel, H, 1972, Cerenkov radiation in photomultiplier windows and the resulting time shift in delayed coincidence time spectra: Nuclear Instruments \& Methods, v 105, p 551-555.

Valenta, R, 1987, US Patent, Reduced background scintillation counting: No. 4, 651,006. 